\title{
Long-term changes and breeding success in relation to nesting structures used by the white stork, Ciconia ciconia
}

\author{
Piotr Tryjanowski ${ }^{1, *}$, Jakub Z. Kosicki', Stanisław Kuźniak \& Tim H. Sparks² \\ 1) Department of Behavioural Ecology, Adam Mickiewicz University, Umultowska 89, PL-61-614 \\ Poznań, Poland (*e-mail: ptasiek@amu.edu.pl) \\ 2) NERC Centre for Ecology and Hydrology, Monks Wood, Abbots Ripton, Huntingdon, \\ Cambridgeshire, PE28 2LS, UK
}

Received 17 Jan. 2008, revised version received 23 June 2008, accepted 1 Oct. 2008

Tryjanowski, P., Kosicki, J. Z., Kuźniak, S. \& Sparks, T. H. 2009: Long-term changes and breeding success in relation to nesting structures used by the white stork, Ciconia ciconia. - Ann. Zool. Fennici 46: 34-38.

Anthropogenic changes have strongly influenced the European landscape. In the last 50 years electric power-line networks have become a conspicuous part of that landscape. From the outset it was known that these lines and their support structures would cause fatalities in the white stork, Ciconia ciconia. From a long-term (1983-2006) study in Poland, we analysed breeding performance in stork nests on four types of structure (chimneys, roofs, trees and electricity poles). Whilst the numbers of nests on both electricity poles and chimneys have increased, there was no significant difference among the four structures in terms of breeding success. Since 1998, over 100 electricity poles in this white-stork breeding area have been modified to include a platform designed to accommodate a stork nest. A comparison between the annual means of nests on electricity poles with and without platforms did not reveal any significant differences in breeding success. However, closer examination of the nests transferred to platforms revealed a slight drop in chick productivity in the year following platform addition, which, however, became significantly higher in the subsequent year. Thus the transfer of nests to platforms appears to have only a short-term adverse effect and may be beneficial in the long run.

\section{Introduction}

For the past 50 years, electric power-lines have been a conspicuous part of the European landscape. When constructed, it was known that these lines and support structures would cause bird fatalities (e.g. Bevanger 1998, Janss 1998, 2000, Infante \& Peris 2003). However, on the positive side, poles/pylons are used as nest platforms by corvids, raptors and especially white storks, Ciconia ciconia (Janss 1998, Garrido \&
Fernandez-Cruz 2003). There is some evidence that during recent decades the white stork has changed the structures on which it nests, and in many parts of its geographical range it frequently builds nests on electricity poles (Muzinic 1999, Garrido \& Fernandez-Cruz 2003, Infante \& Peris 2003, Tryjanowski et al. 2006). To date, however, this phenomenon has only been described in papers comparing results obtained during international white stork censuses, i.e. based on 10-year intervals (Guziak \& Jakubiec 
2006). Earlier, authors described the phenomenon of changes in type of nest structure, but did not attempt to answer the main question: why are electricity poles being used more often for nest-building by storks? One potential reason is that electricity poles offer a safer environment because they are difficult to access by mammalian predators and may, consequently, guarantee higher reproductive success. It is known that nest position plays an important role in breeding success; to date, however, this has only been examined in relation to nest position within a colony (Vergara \& Aguirre 2006).

On the negative side, electrocution and collisions with power lines have been the causes of stork mortality in many regions (Moritzi et al. 2001, Garrido \& Fernandez-Cruz 2003, Schaub et al. 2004). The depth of a stork nest is typically 1-2 $\mathrm{m}$ with a diameter of $0.8-1.5 \mathrm{~m}$ (Creutz 1985, Muzinic 1999), and the nest weighs from 60 to $250 \mathrm{~kg}$. This can add substantially to the weight placed on the power-line support structures, and the excreta of nestling and adult birds deposited on pylons and lines can cause shortcircuits. Therefore, stork nesting on power-line support structures can pose important financial and operational problems for power companies (Muzinic 1999, Muzinic \& Cvitan 2001, Garrido \& Fernandez-Cruz 2003, Infante \& Peris 2003). Consequently, in many parts of Europe active conservation programmes include moving nests located directly on poles to special platforms that, in theory, should reduce adult and young stork fatalities (Jakubiec 1989, Muzinic 1999, Muzinic \& Cvitan 2001). For example, the construction of special platforms for storks on electricity poles started in the early 1980s in Poland and still continues (Jakubiec 1989, Tryjanowski et al. 2006).

In this paper, we examine changes in the choice of nesting structures by a white stork population in Poland, paying special attention to the occupation of electricity poles. We compare the number of chicks fledged on different nesting structures and hypothesise that storks nesting on electricity poles are characterised by a higher reproductive success because of reduced predation. In this context we investigate whether a nest platform affects changes in the breeding parameters of storks and discuss the potential conserva- tion opportunities and drawbacks associated with this kind of protection of white stork nests.

\section{Methods}

The data were collected by the first three authors during 1983-2006 near Leszno in western Poland $\left(51.42-52.00^{\circ} \mathrm{N}, 16.06-16.54^{\circ} \mathrm{E}\right)$. The study site covered $810 \mathrm{~km}^{2}$, and the proportions of habitats were: arable fields $68 \%$, meadows and pastures $6 \%$ with the rest of the area covered by forests, lakes and human settlements (for details see Kosicki \& Kuźniak 2006).

The white stork builds large nests, mostly in human environments; therefore, nests are easy to find and to observe during the breeding period (e.g. Creutz 1985). The population size (number of breeding pairs in the study area), nest location (geographical coordinates of the nests), nesting structure (place where nest was located) and breeding success (number of fledged chicks) of the local population were determined consistently using standard methods (Creutz 1985, Schulz 1998).

Since 1998 over 100 electricity poles in the vicinity of nest sites previously occupied by breeding storks were modified to include a platform designed to accommodate a stork nest, protecting both the storks and the electricity supply.

We used a range of statistical tests to examine changes over time and differences in the productivity of storks between structures, and to compare platform and non-platform nests. The tests used are described in the results section and were, unless otherwise specified, carried out on the means of nests in each of the survey years. We used a significance level of $P<0.05$ but also discussed results within the range of $0.05<P<$ 0.10 . Statistical tests were performed using SPSS for Windows and Minitab. All statistical analyses were carried out according to Zar (1999).

\section{Results}

\section{Year-to-year variation in breeding performance}

Between 1983 and 2006, a total of 2296 nesting attempts at 198 nest sites were monitored of 


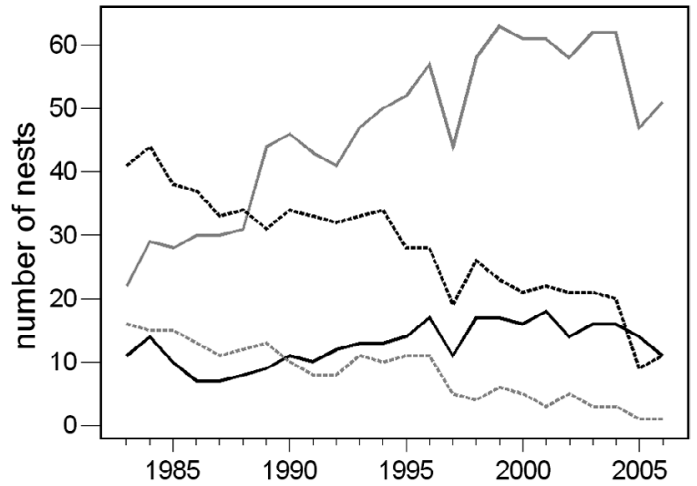

Fig. 1. Changes in structures on which nests were located. Chimney = black solid line, electricity poles = solid grey line, roof $=$ black dotted line, tree = grey dotted line.

which $1754(75 \%)$ were successful and produced 4563 chicks; an average of $1.99(\mathrm{SD}=1.35)$ chicks per nest or $2.60(\mathrm{SD}=0.89)$ chicks per successful nesting.

The number of occupied nests, breeding success and productivity varied from year to year but not in a consistent way (linear regressions of year and number of occupied nests, percentage of successful nesting and mean number of chicks per nest: all $F_{1.22}<0.95$, all $P>0.34$ ). The number of nests occupied per year varied from 71 to 115 (mean $=96)$, the percentage of successful nests per year varied from $58 \%$ to $90 \%$ and the number of chicks per nest per year varied from 1.16 to 2.96 .

Table 1. Mean numbers ( \pm SE) of chicks and percentage of successful nests for the four structure types and significance $(P)$ of differences among the structures. Results from ANOVA of annual means with year and structure as factors, weighted by number of nests contributing to each mean. Least square means and standard errors are given.

\begin{tabular}{lcc}
\hline Structure & Chick number & $\begin{array}{c}\text { Percentage of } \\
\text { successful nests }\end{array}$ \\
\hline Chimney & $1.89 \pm 0.07$ & $74.5 \pm 2.3$ \\
Electricity pole & $1.99 \pm 0.04$ & $75.3 \pm 1.2$ \\
Roof & $2.01 \pm 0.05$ & $78.3 \pm 1.5$ \\
Tree & $1.94 \pm 0.09$ & $76.3 \pm 2.8$ \\
Structure $F_{3,69}$ & 0.83 & 0.97 \\
$P$ & 0.48 & 0.41 \\
\hline
\end{tabular}

\section{Nest structure vs. breeding success}

The nests were distributed as follows: 306 on chimneys (independent structures separate from a building), 673 on roofs, 200 in trees and 1117 on electricity poles. The numbers of nests on electricity poles and on chimneys increased while those on roofs and trees decreased during the 24year sampling period (Fig. 1; linear regression: number of nests and year, all $F_{1,22}>15.49$, all $P \leq 0.001)$.

With the exception of an increasing percentage of successful nests on chimneys (linear regression on year: $\left.F_{1,22}=3.02, P=0.096\right)$ and a decreasing mean number of chicks per nest in trees (linear regression on year, $F_{1,22}=5.21, P$ $=0.032)$ there was little evidence of temporal changes in productivity on the four structures (linear regression on year, remainder all $F_{1,22}<$ 1.18 , all $P>0.29$ ). There was no significant difference among the four structure types in terms of nest productivity or percentage of successful nests (Table 1).

\section{Effect of platform installation on breeding performance}

Nesting material was transferred from poles to the new platforms with inevitable damage and size reduction. In the ensuing years between 16 and 31 electricity pole platforms were occupied. A paired $t$-test between the nine annual means (1998-2006) of nests on electricity poles with and without platforms did not reveal any significant differences in the mean number of chicks per nest (2.06 vs. 1.96) or the percentage of successful nests $\left(79 \%\right.$ vs. $76 \%$; both $t_{8}<0.98, P>$ $0.36)$. However, these figures may be masked by inherent differences in productivity between nests. Consequently, we examined the productivity in 30 nests that had at least two years of data both before and after platform addition. Because the data came from different years we subtracted from each value the mean production on non-platform electricity poles in that year. This adjustment for inter-annual differences revealed a slight drop in chick productivity in the year following platform addition, and a significant increase in productivity in the second year after 
platform addition (paired $t$-test between +1 and +2 years: $\left.t_{29}=2.70, P=0.012\right)($ Fig. 2$)$.

\section{Discussion}

In this paper, we have documented the white stork's change in preference away from traditional nesting structures, particularly from trees, to electricity poles; a pattern that appears to be repeated across its geographical range (Creutz 1985, Schultz 1998, Infante \& Peris 2003), including Poland (Guziak \& Jakubiec 2006, Tryjanowski et al. 2006). Whilst not recorded, we believe there has been little change in the number of each type of structure available to storks in our study area. Therefore, we propose that the changes recorded are a consequence of preferential selection. These changes are of a long-term progressive character and generally the number of nests located on electricity poles is increasing. However, it is difficult to say why storks have changed their nesting structures.

It is known that nest position plays an important role in breeding success, however, to date, this has only properly been tested in nests within a stork colony (Vergara and Aguirre 2006). Generally, nests inside a colony were more productive than nests located on the periphery. This has been shown to be important for the western (Spanish) population where the white stork is a colony breeder (Creutz 1995, Schulz 1998, Vergara \& Aguirre 2006). In the eastern population, storks are mainly solitary nesters with a loose colony structure in some sites rich in food resources (Guziak \& Jakubiec 2006, Tryjanowski et al. 2006). Therefore, breeding habitat is likely to have a greater effect on white stork nest productivity (Vergara \& Aguirre 2006, Kosicki et al. 2007) than nesting structure per se (Janss \& Sanchez 1997, Tryjanowski et al. 2005).

This study did not reveal any major productivity benefits of nesting on electricity poles, although productivity of nests in trees was in decline, possibly due to predation by mammals such as the stone marten Martes foina (Jakubiec 1991, Schultz 1998). Changes in the preference of nesting sites are not because of a lack of suitable trees and it is easier to suggest negative consequences of nesting on electricity poles. For

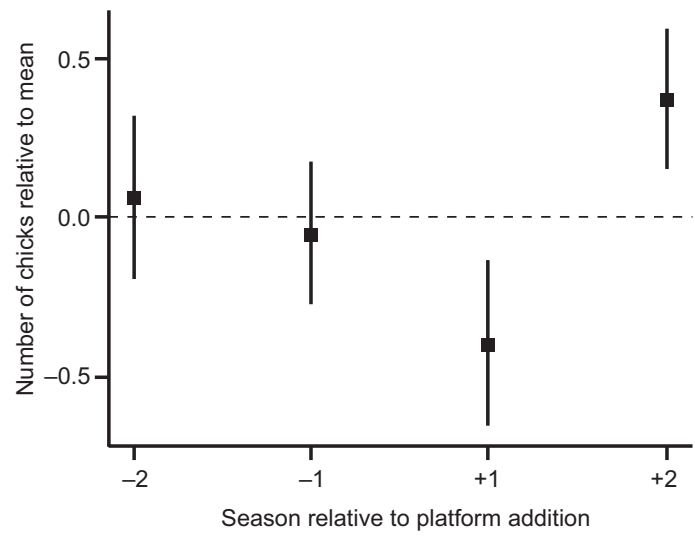

Fig. 2. Relative mean \pm SE chick numbers at nests receiving platforms for two years before and two years after platform addition.

example, it has been suggested that electromagnetic fields may affect white stork reproduction and therefore pairs breeding on electricity poles (Balmori 2005). Moreover, nesting on electricity poles incurs higher risks of electrocution, especially of young storks during their first flights (Jakubiec 1991, Garrido \& Fernandez-Cruz 2003, Schaub et al. 2004). In order to reduce these possibilities, electric power companies and conservationists have provided nest platforms for white storks. Therefore, the process of electricity pole occupation may be further influenced by human activity. During construction, and moving an existing nest to a platform, part of the nest material is removed and, therefore, nests are shallower and lighter (Muzinic 1999, Muzinic \& Cvitan 2001). From a practical point of view this is probably necessary. However, as we have shown in this study, it may reduce white stork breeding success in the following year, but recovery and even greater productivity may be achieved by year two. We link these negative changes in breeding success to the destruction of part of the nest material, causing changes in nest microclimate, and in consequence to a chick's endothermy (Tortosa \& Villafuerte 1999). Additionally, changes in nest size and construction may influence the general attractiveness of the nest site. Because the white stork has a very high nest fidelity (Chernetsov et al. 2006, Vergara et al. 2006), especially in older birds, this suggests that new sites (in this context - poles) are 
occupied by young storks, i.e. with potentially lower breeding success. Therefore, from a conservation point of view, the movement of a nest to a special platform appears to have only minor negative effects in the following year (e.g. also Muzinic 1999, Muzinic \& Cvitan 2001).

White stork populations appear to be abandoning traditional nest structures and, in the studied population, half of the nests were on recent man-made structures such as electricity poles. Contrary to expectation, the productivity of nests on electricity poles does not seem to be higher than on traditional structures, but the recent addition of specially built nest platforms to electricity poles seems to be beneficial to stork reproduction. We recommend that this is studied further when more data on productivity of platform nests become available.

\section{Acknowledgements}

The study was partially supported by UAM/AM grant (PBWB 703/2006) and Polish Ministry of Science grant N N304 078035 . We thank Lizzy Carroll, two anonymous referees and the editor for constructive comments on an earlier version of the manuscript.

\section{References}

Balmori, A. 2005: Possible effects of electromagnetic fields from phone masts on a population of white stork (Ciconia ciconia). - Electromagnetic Biology and Medicine 24: 109-119.

Bevanger, K. 1998: Biological and conservation aspects of bird mortality caused by electricity power lines: a review. - Biological Conservation 86: 67-76.

Chernetsov, N., Chromik, W., Dolata, P. T., Profus, P. \& Tryjanowski, P. 2006: Sex-related natal dispersal of white storks (Ciconia ciconia) in Poland: how far and where to? - Auk 123: 1103-1109.

Creutz, G. 1985: Der Weißstorch Ciconia ciconia. - A. Ziemsen Verlag, Wittenberg Lutherstadt.

Garrido, J. R. \& Fernandez-Cruz, M. 2003: Effects of power lines on a White Stork Ciconia ciconia population in central Spain. - Ardeola 50: 191-200.

Guziak, R. \& Jakubiec, Z. (ed.) 2006: White stork Ciconia ciconia (L.) in Poland in 2004. Results of the VIth International White Stork Census. - PTOP "pro Natura", Wrocław.
Infante, O. \& Peris, S. 2003: Bird nesting on electric power supports in northwestern Spain. - Ecological Engineering 20: 321-326.

Jakubiec, Z. 1989: On protection of white stork nests located on electrical pylons. - Energetyka 43: 283-286.

Jakubiec, Z. 1991: Causes of breeding losses and adult mortality in white stork Ciconia ciconia (L.) in Poland. - Studia Nature 37: 107-124.

Janss, G. F. E. 1998: Nests of white storks on electric utility towers. - Wildlife Society Bulletin 26: 274-278.

Janss, G. F. E. 2000: Avian mortality from power lines: a morphologic approach of a species-specific mortality. - Biological Conservation 95: 353-359.

Janss, G. F. E. \& Sanchez, I. 1997: Productivity of white storks at different nest sites. - Ardeola 44: 101-103.

Kosicki, J. Z. \& Kuźniak, S. 2006: Long-term population size and productivity dynamics of a local white stork Ciconia ciconia population in Wielkopolska. - In: Tryjanowski, P., Sparks, T. H. \& Jerzak, L. (eds.), The white stork in Poland: studies in biology, ecology and conservation: 23-33. Bogucki Wydawnictwo Naukowe, Poznań.

Kosicki, J. Z., Sparks, T. H. \& Tryjanowski, P. 2007: House sparrows benefit from the conservation of white storks. - Naturwissenschaften 94: 412-415.

Moritzi, M., Spaar, R. \& Biber, O. 2001: Todesursachen in der Schweiz beringter Weißstörche (Ciconia ciconia) von 1947-1997. - Vogelwarte 41: 44-52.

Muzinic, J. 1999: A frame for white stork nests. - Israel Journal of Zoology 45: 497-499.

Muzinic, J. \& Cvitan, I. 2001: Choice of nest platform material for the white stork (Ciconia ciconia). - Israel Journal of Zoology 47: 167-171.

Schaub, M., Pradel R. \& Lebreton, J. D. 2004: Is the reintroduced white stork (Ciconia ciconia) population in Switzerland self-sustainable? - Biological Conservation 119: 105-114.

Schulz, H. 1998: Ciconia ciconia white stork. - Birds of the Western Palearctic, Update 2: 69-105.

Tortosa, F. S. \& Villafuerte, R. 1999: Effect of nest microclimate on effective endothermy in white stork Ciconia ciconia nestlings. - Bird Study 46: 336-341.

Tryjanowski, P., Sparks, T. \& Profus, P. 2005: Uphill shifts in the distribution of the white stork Ciconia ciconia in southern Poland: the importance of nest quality. - Diversity and Distributions 11: 219-223.

Tryjanowski, P., Sparks T. H. \& Jerzak, L. (eds.) 2006: The white stork in Poland: studies in biology, ecology and conservation. - Bogucki Wydawnictwo Naukowe, Poznań.

Vergara, P. \& Aguirre, J. I. 2006: Age and breeding success related to nest position in a white stork Ciconia ciconia colony. - Acta oecologica 30: 414-418.

Vergara, P., Aguirre, J. I., Fargallo, J. A. \& Davila, J. A. 2006: Nest-site fidelity and breeding success in white stork Ciconia ciconia. - Ibis 148: 672-677.

Zar, J. H. 1999: Biostatistical analysis, 4th ed. - Prentice Hall, New Jersey. 